\title{
Non-fatal case of Crimean-Congo haemorrhagic fever imported into the United Kingdom (ex Bulgaria), June 2014
}

S Lumley (Sarah.Lumley@phe.gov.uk) ${ }^{1}$, B Atkinson ${ }^{1}$, S D Dowall ${ }^{1}$, J K Pitman², S Staplehurst ${ }^{3}$, J Busuttil ${ }^{3}$, A J Simpson ${ }^{3}$, E J

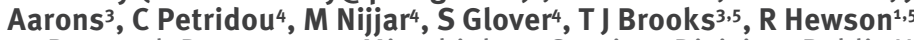

1. Research Department, Microbiology Services Division, Public Health England, Porton Down, Salisbury, United Kingdom

2. Operations Department, Microbiology Services Division, Public Health England, Porton Down, Salisbury, United Kingdom

3. Rare and Imported Pathogens Laboratory, Microbiology Services Division, Public Health England, Porton Down, Salisbury, United Kingdom

4. University Hospital Southampton, NHS Foundation Trust, Southampton, United Kingdom

5. National Institute for Health Research Health Protection Research Unit in Emerging and Zoonotic Infections, Liverpool, United Kingdom

Crimean-Congo haemorrhagic fever (CCHF) was diagnosed in a United Kingdom traveller who returned from Bulgaria in June 2014. The patient developed a moderately severe disease including fever, headaches and petechial rash. CCHF was diagnosed following identification of CCHF virus (CCHFV) RNA in a serum sample taken five days after symptom onset. Sequence analysis of the CCHFV genome showed that the virus clusters within the Europe 1 clade, which includes viruses from eastern Europe.

\section{Clinical description}

A British man in his early 70 s presented to a hospital in the United Kingdom (UK) in June 2014 following a recent trip to Bulgaria. He had a history of paroxysmal atrial fibrillation for which he was taking warfarin, but was otherwise fit and well. He travelled with his spouse on 26 May 2014 to a rural area of Burgas Province near the Black Sea. On 18 June, he was bitten by a tick while outdoors. He removed the tick that evening without difficulty. Approximately five days previously, he had removed a tick from a cat and crushed it between his fingers.

He became abruptly unwell on 22 June, with fever, sweats, cough, sore throat, myalgia, headache, diarrhoea and two episodes of collapse. He was admitted overnight to a private hospital on 25 June and returned to the UK the following day, where he was admitted to his local university teaching hospital.

On arrival, the patient was febrile with a petechial rash on his legs and bilateral crepitations on chest auscultation. There was no overt bleeding or bruising. He was thrombocytopenic, with a platelet count of $26 \times 10^{9} / \mathrm{L}$ (norm: $150-400 \times 10^{9} / \mathrm{L}$ ), neutrophils of $1.1 \times 10^{9} / \mathrm{L}$ (norm: $2.0-7.5 \times 10^{9} / \mathrm{L}$ ) and lymphocytes of $0.4 \times 10^{9} / \mathrm{L}$ (norm: $1.5-4.0 \times 10^{9} / \mathrm{L}$ ). His renal function was normal and the level of $\mathrm{C}$-reactive protein was mildly elevated, at $22 \mathrm{mg} / \mathrm{L}$ (norm: $0-7.5 \mathrm{mg} / \mathrm{L}$ ) as was that of alanine aminotransferase (ALT), at 64 units (U)/L (norm: 10-40 $\mathrm{U} / \mathrm{L}$ ). He was isolated in a side room and treated with antibiotics including doxycycline to cover the possibility of tick-borne rickettsial infection. Over the following 48 hours, his platelet count fell to a low of $15 \times 10^{9} / \mathrm{L}$ and neutrophils to $0.7 \times 10^{9} / \mathrm{L}$.

Following discussion with the UK's Imported Fever Service, serum, urine and blood samples were sent to the Rare and Imported Pathogens Laboratory at Public Health England (PHE), Porton Down, to screen for tick-borne infections including rickettsia, tick-borne encephalitis and CCHF, in addition to other potential arboviral zoonoses.

\section{Laboratory findings}

Initial diagnosis of CCHFV infection was made using a published real-time reverse transcription (RT)-PCR assay designed to detect the highly conserved panhandle loop formation of the CCHFV S segment [1]. A serum sample taken five days post onset of symptoms produced a positive result, with an estimated viral load of $1.5 \times 10^{5} \mathrm{~S}$ segment copies/mL in serum; urine and blood samples taken 10 days after symptom onset tested negative.

The serum sample taken five days post onset of symptoms was negative for CCHFV-specific antibodies tested for by enzyme-linked immunosorbent assay (ELISA) (in-house [2] and commercial Vector-Best assays) and immunofluorescence (Euroimmun); all assays demonstrated the production of reactive IgM and IgG antibodies in the samples taken 10 days post onset of symptoms. 


\section{FIGURE}

Maximum likelihood phylogenetic tree of complete

Crimean-Congo haemorrhagic fever virus S segments

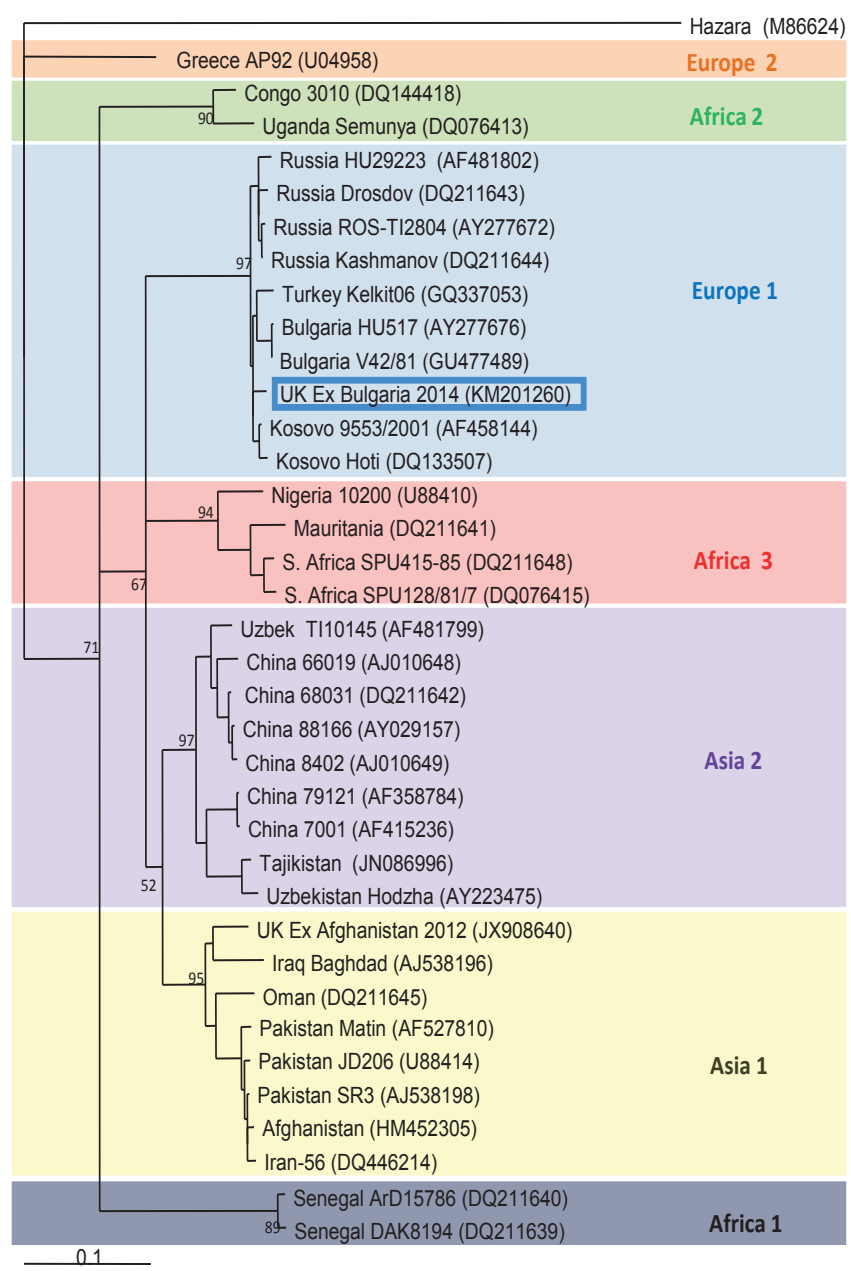

The tree was constructed to determine the similarity and origin of the strain isolated from a United Kingdom traveller who returned from Bulgaria in late June 2014 . It is rooted with the closely related Hazara virus. The genomic S segment of the virus from the UK traveller (GenBank accession number: KM201260) clusters with the Europe 1 group, showing close similarity to other strains from eastern Europe. All strains are listed with associated GenBank accession numbers for the S segment of the genome.

CCHFV was isolated in vitro from the PCR-positive serum sample within the Containment Level 4 laboratory at PHE Porton, using the human $\mathrm{SW}_{13}$ cell line. Sequence data for the complete $S$ segment of the CCHFV genome were obtained using a sequencing strategy based on previously described protocols [3]. The sequence was submitted to GenBank on 15 July (GenBank accession number: KM201260). Phylogenetic analysis of sequence data using Clustal W placed this virus within the Europe 1 clade [4], along with strains of CCHFV isolated from nearby regions of eastern Europe (Figure).

\section{Control measures}

CCHF can be transmitted nosocomially, especially in cases presenting with extensive haemorrhagic manifestations or those requiring surgical intervention [5-9]. Therefore, following the laboratory diagnosis on 2 July 2014, the use of full personal protective equipment was mandated and contact tracing was commenced. As the patient was clinically improving and had no overt bleeding, care was continued at the local hospital rather than the national High Security Infectious Disease Unit. The patient made a steady improvement and was discharged on 9 July with normal blood indices. No onward transmission to contacts has been identified.

\section{Discussion and conclusions}

This report represents the second confirmed case of CCHF imported into the UK, the first being a case with a fatal outcome reported in 2012 [10]. In comparison with the case identified in 2012, who presented at hospital with overt haemorrhagic manifestations, the patient reported here suffered from a milder form of disease, without extensive haemorrhaging. The estimated viral load was 2-3 logs lower than that of the fatal case in 2012, when comparing samples taken five days post onset of symptoms; lower viral loads in the first week of illness are associated with patient survival [11]. Sequence analysis of the CCHFV $S$ segment amplified from the patient's serum showed homology with other stains of CCHFV obtained from the same region of Europe.

The differences in clinical presentation and outcome between the two confirmed cases highlight the difficulties in rapidly identifying CCHF patients in the hospital setting. Early diagnosis is critical in reducing the potential for nosocomial transmission; however, the variation in disease severity and clinical symptoms increase the potential for a missed diagnosis. The Imported Fever Service, run by PHE in partnership with National Health Service (NHS) specialist tropical disease units in Liverpool and London, provides 24-hour on-call clinical advice and diagnostic capabilities for travel-related febrile illnesses, including viral haemorrhagic fevers [12]. The prompt identification of the pathogen, in both CCHF cases imported into the UK allowed infection control and public health actions to be taken in order to identify and minimise the potential for onward transmission.

To the best of our knowledge, this is the fourth laboratory-confirmed importation of CCHF into a non-endemic European country, following the fatal case imported into the UK from Afghanistan in 2012 [10], the medical evacuation of a United States soldier from Afghanistan into Germany in 2009 that resulted in a fatal outcome [13] and a non-fatal case imported into France from Senegal in 2004 [14]. In addition to these confirmed cases, a suspected case of CCHF was imported into the UK from Zimbabwe in 1997 [15] and an unpublished 
case was imported into Germany from Bulgaria in 2001 [16].

CCHF is considered endemic in several parts of the Balkans, with over 1,500 human cases registered in Bulgaria up to $2009[17,18]$. Seroprevalence studies have shown human exposure to CCHFV in numerous districts across the country, with the highest rates in the Burgas region, where the UK traveller in this report was based [19]. As the route of infection is suspected to be via the bite of an infected tick, this case highlights the importance of tick awareness and bite prevention measures when travelling to regions endemic for pathogenic arboviral zoonoses including CCHF.

\section{Acknowledgements}

The authors would like to acknowledge the work of staff in the Rare and Imported Pathogens Laboratory for their involvement in processing samples in addition to the work by staff of PHE and the NHS in providing clinical care, infection control, contact tracing and surveillance.

\section{Conflict of interest}

None declared.

\section{Authors' contributions}

SL, BA, CP, MN, SG and RH wrote the paper; SL, BA, SD, JP, SS and JB performed laboratory diagnostics and viral characterisation; AS, EA and TB provided clinical and infection control advice; CP, MN and SG provided clinical care. All authors reviewed the manuscript before submission.

\section{References}

1. Atkinson B, Chamberlain J, Logue $\mathrm{CH}$, Cook N, Bruce C, Dowall SD, et al. Development of a real-time RT-PCR assay for the detection of Crimean-Congo hemorrhagic fever virus. Vector Borne Zoonotic Dis. 2012;12(9):786-93.

http://dx.doi.org/10.1089/vbz.2011.0770

2. Dowall SD, Richards KS, Graham VA, Chamberlain J, Hewson $R$. Development of an indirect ELISA method for the parallel measurement of IgG and IgM antibodies against CrimeanCongo haemorrhagic fever (CCHF) virus using recombinant nucleoprotein as antigen. J Virol Methods. 2012;179(2):335-41. http://dx.doi.org/10.1016/j.jviromet.2011.11.020

3. Atkinson B, Chamberlain J, Jameson LJ, Logue CH, Lewis J, Belobrova EA, et al. Identification and analysis of CrimeanCongo hemorrhagic fever virus from human sera in Tajikistan. Int J Infect Dis. 2013;17(11):e1031-7. http://dx.doi.org/10.1016/j.ijid.2013.04.008

4. Hewson R, Chamberlain J, Mioulet V, Lloyd G, Jamil B, Hasan $R$, et al. Crimean-Congo haemorrhagic fever virus: sequence analysis of the small RNA segments from a collection of viruses world wide. Virus Res. 2004;102(2):185-9.

http://dx.doi.org/10.1016/j.virusres.2003.12.035

5. Hasan Z, Mahmood F, Jamil B, Atkinson B, Mohammed $M$, Samreen A, et al. Crimean-Congo hemorrhagic fever nosocomial infection in an immunosuppressed patient, Pakistan: case report and virological investigation. J Med Virol. 2013;85(3):501-4.

http://dx.doi.org/10.1002/jmv.23473

6. Ergönül 0. Crimean-Congo haemorrhagic fever. Lancet Infect Dis. 2006;6(4):203-14. http://dx.doi.org/10.1016/S1473-3099(06)70435-2

7. Mardani M, Keshtkar-Jahromi M, Ataie B, Adibi P. CrimeanCongo hemorrhagic fever virus as a nosocomial pathogen in Iran. Am J Trop Med. Hyg. 2009;81(4):675-8.

http://dx.doi.org/10.4269/ajtmh.2009.09-0051
8. Tishkova FH, Belobrova EA, Valikhodzhaeva M, Atkinson B, Hewson R, Mullojonova M. Crimean-Congo hemorrhagic fever in Tajikistan. Vector Borne Zoonotic Dis. 2012;12(9):722-6. http://dx.doi.org/10.1089/vbz.2011.0769

9. Aradaib IE, Erickson BR, Mustafa ME, Khristova ML, Saeed NS, Elageb RM, et al. Nosocomial outbreak of Crimean-Congo hemorrhagic fever, Sudan. Emerging Infect Dis. 2012;16(5):8379. http://dx.doi.org/10.3201/eid1605.091815

10. Atkinson B, Latham J, Chamberlain J, Logue C, O'Donoghue L, Osborne J, et al. Sequencing and phylogenetic characterisation of a fatal Crimean - Congo haemorrhagic fever case imported into the United Kingdom, October 2012. Euro Surveill. 2012;17(48): $\mathrm{pii}=20327$.

11. Duh D, Saksida A, Petrovec M, Ahmeti S, Dedushaj I, Panning $M$, et al. Viral load as predictor of Crimean-Congo hemorrhagic fever outcome. Emerging Infect. Dis. 2007;13(11):1769-72. http://dx.doi.org/10.3201/eid1311.070222

12. Public Health England (PHE). Imported Fever Service. London: PHE. [Accessed 11 Jul 2014]. Available from: http://www.hpa.org.uk/ProductsServices/ MicrobiologyPathology/LaboratoriesAndReferenceFacilities/ RareAndImportedPathogensDepartment/ ImportedFeverService/

13. Olschläger S, Gabriel M, Schmidt-Chanasit J, Meyer M, Osborn $\mathrm{E}$, Conger NG, et al. Complete sequence and phylogenetic characterisation of Crimean-Congo hemorrhagic fever virus from Afghanistan. J Clin Virol. 2011;50(1):90-2. http://dx.doi.org/10.1016/j.jcv.2010.09.018

14. Jauréguiberry S, Tattevin P, Tarantola A, Legay F, Tall A, Nabeth $\mathrm{P}$, et al. Imported Crimean-Congo hemorrhagic fever. J Clin Microbiol. 2005;43(9):4905-7. http://dx.doi.org/10.1128/JCM.43.9.4905-4907.2005

15. Stuart J. Suspected case of Crimean/Congo haemorrhagic fever in British traveller returning from Zimbabwe. Euro Surveill. 1998;2(8): $\mathrm{pii}=1256$.

16. European Network for Diagnostics of "Imported" Viral Diseases (ENVID). Import of VHF and SARS to Europe. ENVID. [Accessed 12 Jul 2014]. Available from: http://www.enivd.de/over.htm

17. Vescio FM, Busani L, Mughini-Gras L, Khoury C, Avellis L, Taseva $E$, et al. Environmental correlates of Crimean-Congo haemorrhagic fever incidence in Bulgaria. BMC Public Health. 2012;12:1116. http://dx.doi.org/10.1186/1471-2458-12-1116

18. Papa A, Christova I, Papadimitriou E, Antoniadis A. CrimeanCongo hemorrhagic fever in Bulgaria. Emerg Infect Dis. 2004;10(8):1465-7. http://dx.doi.org/10.3201/eid1008.040162

19. Christova I, Gladnishka T, Taseva E, Kalvatchev N, Tsergouli K, Papa A. Seroprevalence of Crimean-Congo hemorrhagic fever virus, Bulgaria. Emerg Infect Dis. 2013;19(1):177-9. http://dx.doi.org/10.3201/eid1901.120299 